\title{
The use of Microsatellite Markers in Genetic Variation Analysis of Some Introduced Rubber Tree (Hevea brasiliensis) Clones Cultivated in Ghana
}

\author{
A. Antwi-Wiredu ${ }^{*}$, S. Amiteye ${ }^{2}$, A. T. Asare' ${ }^{2}$ R. Kusi-Adjei², R. G. Diawuoh², C. O. Aryee ${ }^{3}$, \\ and G. Y. P. Klu ${ }^{4}$
}

Received: $28^{\text {th }}$ March 2018 / Accepted: $25^{\text {th }}$ April 2018

\begin{abstract}
Purpose: Genetic makers are indispensable in the genetic quantification and characterization of plant species of which rubber tree is no exception. Markers have been used severally in genetic identification and diversity analysis of rubber tree species. However, in Ghan genetic diversity and relatedness among introduced rubber tree species are limited. The study is aimed to use microsatellite markers to assess the genetic variability and evaluate genetic relationships among clones of Hevea brasiliensis cultivated in Ghana.
\end{abstract}

Research Method: Genomic DNA was extracted from fresh rubber leaves following the Cetyltrimethyl Ammonium Bromide (CTAB) protocol. The five (5) different SSR primers used for the analysis were hmct1, hmac4, hmct5, gSSR 212 and gSSR 194 .

Findings: The five SSR markers showed some degree of relatedness among the rubber clones which suggested genetic similarity (IRCA317-5, IRCA41-2, IRCA331-6, IRCA230-4, IRCA109-3, and B8-23) and diversity (K2-18, IRCA840-7, PB217-8, PB217-10, and IRCA317-16) among the clones irrespective of their geographical area of collection.

Research Limitation: The unavailability of polivinylpolipyrolidon (PVPP) and polyacrylamide gel (PAGE).

Original Value: The results from the study depict that relatively some rubber clones of interest could be selected for future breeding and propagation programmes in Ghana.

Keywords: Microsallites, Diversity, Similarity, Markers, Rubber Clones

\section{INTRODUCTION}

In order to ensure a successful breeding programme, information about the germplasm diversity and genetic relatedness is very necessary (Mukhtar et al., 2002). Information of such nature can be obtained from pedigree analysis, morphological traits characterization or molecular marker analysis (Mohammadi and Prasanna, 2003). There is a limitation in genetic differentiation in plant species based on morphological characterization. Thus, the use of molecular markers presents a more promising technique for easy resolution of genetic differentiation.
This is particularly important in rubber tree where there is lack of useful morphological traits for clonal distinction (Besse et al., 1993).

\footnotetext{
${ }^{1 *}$ Forestry Research Institute of Ghana, P. O. Box UP 63, KNUST-Kumasi, Ghana.

tonysnas@gmail.com

ORCID http://orcid.org/0000-0002-1473-0966

${ }^{2}$ Biotechnology and Nuclear Agriculture Research Institute, Ghana Atomic Energy Commission, P. O. Box LG 80, LegonAccra. Ghana.

${ }^{3}$ Cocoa Research Institute of Ghana, P. O. Box 8, New TafoAkim, Ghana.

${ }^{4}$ School of Nuclear and Allied Sciences, University of Ghana, P. O. Box AE1, Atomic Energy-Accra. Ghana.
} 
Genetic markers are useful in labeling and amplifying DNA and highlighting its variations among individual organisms. According to Karp et al., (1997), molecular markers provide genetic information on genetic distances to identify particular divergent sub-populations harbouring valuable genetic traits, identification of duplicate accessions, monitor changes in genetic structure; and characterization with respect to genetic diversity within collections. Markers may extend and complement characterization based on morphological or biochemical descriptions with more detailed passport data and accuracy than classical phenotypic data (Hodgkin et al., 1995).

Investigations into the genetic diversity of the rubber tree using of molecular markers have been reported extensively (Lekawipat et al., 2003; Saha et al., 2005; Lam et al., 2009; Gouvéa et al., 2010; Oktavia et al., 2011; Feng et al., 2012). In recent past, genetic markers have served as powerful aids in understanding the genetics of Hevea brasiliensis as well as assisted in clonal origin and identification.

Among all the markers, microsatellite markers are deemed the most suitable for genetic studies because they combine co-dominance and high polymorphism with abundance, locus specificity and uniform dispersion in plant genomes (Kalia et al., 2011). A combination of four microsatellite markers was used to discriminate uniquely 27 Hevea clones and also to generate some clonespecific allelic profiles (Saha et al., 2005). The rubber breeding objective is to provide superior and mature budded clones for latex production, rubber-wood production, quality rubber products and environmental protection through carbon sequestration (Venkatachalam et al., 2013). Hevea breeding is time-consuming and expensive. Thus, molecular markers such as microsatellites can be used to reduce the time required for breeding the tree crop (Mantello et al., 2012). Similar microsatellite priming sites are more likely to be shared by closely related species but often, transfer of these functional markers also occur among distantly related species (Lorieux et al., 2000). Between the two types of Simple Sequence Repeats (SSRs), Expressed Sequences Tags (EST-SSR) have a stronger transferability among genera and species and this has successfully been applied in Hevea brasiliensis than genomic SSR (gSSR) (Lindqvist et al., 2006; Feng et al., 2009). Microsatellites are more efficient in genetic diversity analysis (Laborda et al., 2005; Saha et al., 2005).

In Ghana, genetic studies using molecular markers to diagnose, quantify and characterize genetic variations/diversities in rubber clones have received little attention and, therefore, hinders breeding efforts of rubber tree improvement. Since the introduction of rubber in Ghana in 1898, there has not been any critical research into genetic variation analysis and relatedness among various clones grown in the country. It is, therefore, necessary to use SSR markers to study the genetic diversity and similarity of the various local Hevea clones being grown by out growers in the country. The study will be useful in parent-tree selection for Hevea breeding and propagation programme, germplasm evaluation and genetic characterization of traits of agronomic interest. The objective of this study is to use microsatellite markers to identify and assess genetic variability and also evaluate the genetic relationships among some introduced clones of Hevea brasiliensis cultivated in Ghana.

\section{MATERIALS AND METHODS}

Twenty-three (23) $H$. brasiliensis clones, collected from Plantations Socfinaf Ghana Ltd (PSG), Takoradi (GT1, PB 217, RRIM 703, RRIC 100, IRCA 230, IRCA 41, IRCA 317, IRCA 331); Ghana Rubber Estate Ltd (GREL), Western Region (GT1, IRCA 41, IRCA 109, IRCA 230, IRCA 317, IRCA 331, IRCA 840, PB 217); Forest and Horticultural Crops Research Centre (FOHCREC), Kade, University of Ghana (K1, K2, K3); Plant Genetic Resource Research Institute (PGRRI), Bunso (B1, B5, 
B7, B8) were used for this study. Fresh leaves were collected from each clone and stored at $-20^{\circ} \mathrm{C}$ after thoroughly washing them.

\section{DNA Extraction}

Total genomic DNA was extracted from fresh rubber leaves following the Cetyltrimethyl Ammonium Bromide (CTAB) protocol of Doyle and Doyle (1990) with some modifications. The DNA pellet was washed with $70 \%$ ethanol two times and dried at room temperature. The quality of DNA was confirmed by agarose gel electrophoresis $(0.8 \%$ agarose $)$ with ethidium bromide in TAE buffer $(40 \mathrm{mM}$ Tris-acetate $\mathrm{pH}$ 8.0, $1 \mathrm{mM}$ EDTA) and exposed to UV light and photographed. Samples were loaded into agarose gel with $0.25 \%$ bromophenol blue, $0.25 \%$ Xylene cyanol FF and 30\% glycerol in water as loading buffer. Thereafter, $20 \mu \mathrm{l}$ of each DNA was diluted with sterilize distilled water to $100 \mu$ l before PCR amplification.

\section{PCR Amplification of DNA Sample}

PCR amplification of DNA was performed following a protocol described by Saha et al., (2005). The amplification reaction was carried out in $25 \mu \mathrm{l}$ final volume containing $20 \mathrm{ng}$ of genomic DNA $(1 \mu \mathrm{l}), 25 \mathrm{mM}(50 \mu \mathrm{l}), 10 \mathrm{x}$ Taq buffer $(50 \mu \mathrm{l}), 0.2 \mu \mathrm{M}(25 \mu \mathrm{l})$ each of the forward and reverse primers, $200 \mu \mathrm{M}$ dNTPs $(5 \mu \mathrm{l})$ and 0.7 units of Taq polymerase $(5 \mu 1)$. Three out of the four most applied SSR marker pairs in $H$. brasiliensis genetic variability analysis identified from the genomic library of $H$. brasiliensis (Roy et al., 2004; Saha et al., 2005) together with two other primer pairs reported by Pootakham et al., (2012) were used for the study. These five (5) different SSR primers are hmct1, hmac4, hmct5, gSSR212 and gSSR194.

The temperature profile involved an initial denaturation step of 5 minutes at $95^{\circ} \mathrm{C}$ followed by a touch-down PCR programme. Temperature profiles of touch-down PCR for seven cycles were as follows: $94^{\circ} \mathrm{C}$ for $30 \mathrm{sec}$, annealing at $\left(63^{\circ} \mathrm{C}\right.$ for 1 minute and $53^{\circ} \mathrm{C}$ for $30 \mathrm{sec}$ each depends on primer pairs), and decreased $1{ }^{\circ} \mathrm{C}$ for seven cycles, and finally $72^{\circ} \mathrm{C}$ for 1 minute. It was further followed by a normal cycling of $94^{\circ} \mathrm{C}$ for $30 \mathrm{sec}, 56^{\circ} \mathrm{C}$ for 1 minute, $72^{\circ} \mathrm{C}$ for 1 minute for 23 cycles and a final extension at $72^{\circ} \mathrm{C}$ for 10 minutes. The touch-down protocol is used to eliminate stuttering and artifact bands. PCR amplicons were ran on 3\% agarose gel matrix stained with ethidium bromide to a final concentration of $0.5 \mu \mathrm{g} / \mathrm{ml}$. Eight $(8 \mu \mathrm{l})$ PCR products were loaded into the wells and ran at $100 \mathrm{~V}$ for 1 hour and were visualized using a UV transilluminator.

\section{RESULTS}

All the five different microsatellites produced bands for the evaluation of genetic diversity/ similarity among the 23 rubber clones from four (4) different geographical areas of Ghana. The primers provided monomorphic patterns and the number of bands for each primer varied from 11 to 16 with an average of 13.75 fragments per primer. The amplified products ranged from 100 to 650 base pairs in size which was in consonant with the findings of Sirisom and Te-chato (2014).

\section{Genetic Diversity/Similarity and Cluster Analysis}

Figure 02 shows a dendrogram generated using Unweighted Pair Group Method with Arithmetic Mean (UPGMA) from NYSYSpc version 2.02i. The bands generated from SSR (Figure 01) were used to plot the dendrogram/cluster to study the genetic similarity and diversity or variation among the clones collected. A dendrogram generated from the UPGMA cluster analysis distinguished 23 clones of $H$. brasiliensis from four (4) different geographical areas of Ghana into two clusters (A and B) at genetic distance of $36 \%$. Cluster A was further divided into two sub-clusters (AI and AII) at genetic distance of $53.6 \%$. Sub-cluster AI consisted of H. brasiliensis clones K2-18 (Kade) and AII of clones GT1-9 (PSG), IRCA317-5 and IRCA412 (GREL) 


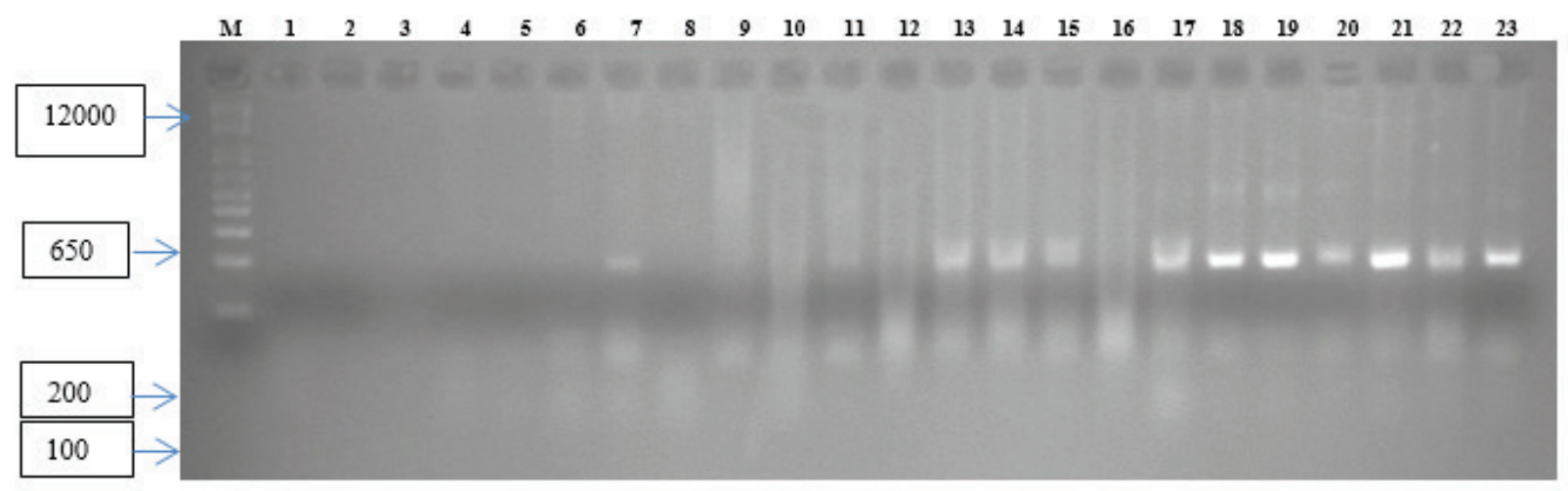

Figure 01A: Thebandingpattern of markerhmet5 on rubber clones numbered 1-23. Forward primer: GTTTTCCTCCGCAGACTCAG, Reverse primer: ATCCACCAAATAAGGCATGA.

GREL (GT1-1, IRCA 41-2, IRCA 109-3, IRCA 230-4, IRCA 317-5, IRCA 331-6, IRCA 840-7, PB 217-8); PSG (GT1-9, PB 217-10, RRIM 703-11, RRIC 100-12, IRCA 230-13, IRCA 41-14, IRCA 317-15, IRCA 331-16); Kade (K1-17, K2-18, K3-19); and Bunso (B1-20, B5-21, B7-22, B8-23) and M-1kb ladder.

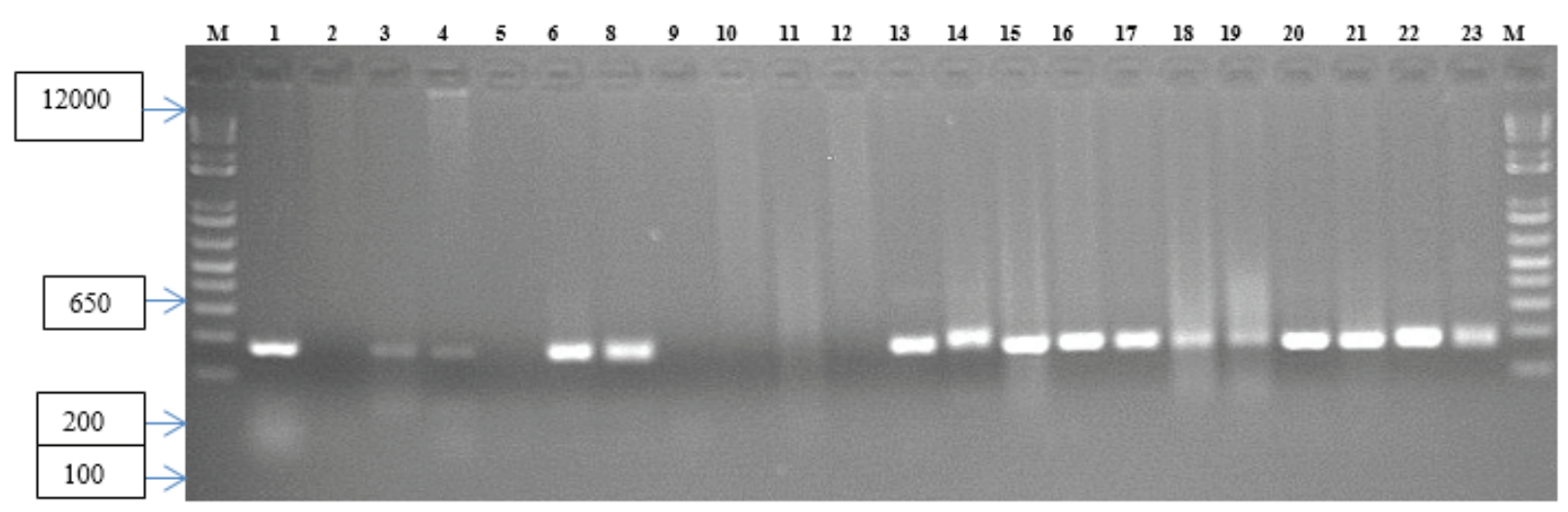

Figure 01B: The banding pattern of marker gSSR212 on rubber clones numbered 1-23. Forward primer: GTTTTCCTCCGCAGACTCAG, Reverse primer: ATCCACCAAATAAGGCATGA.

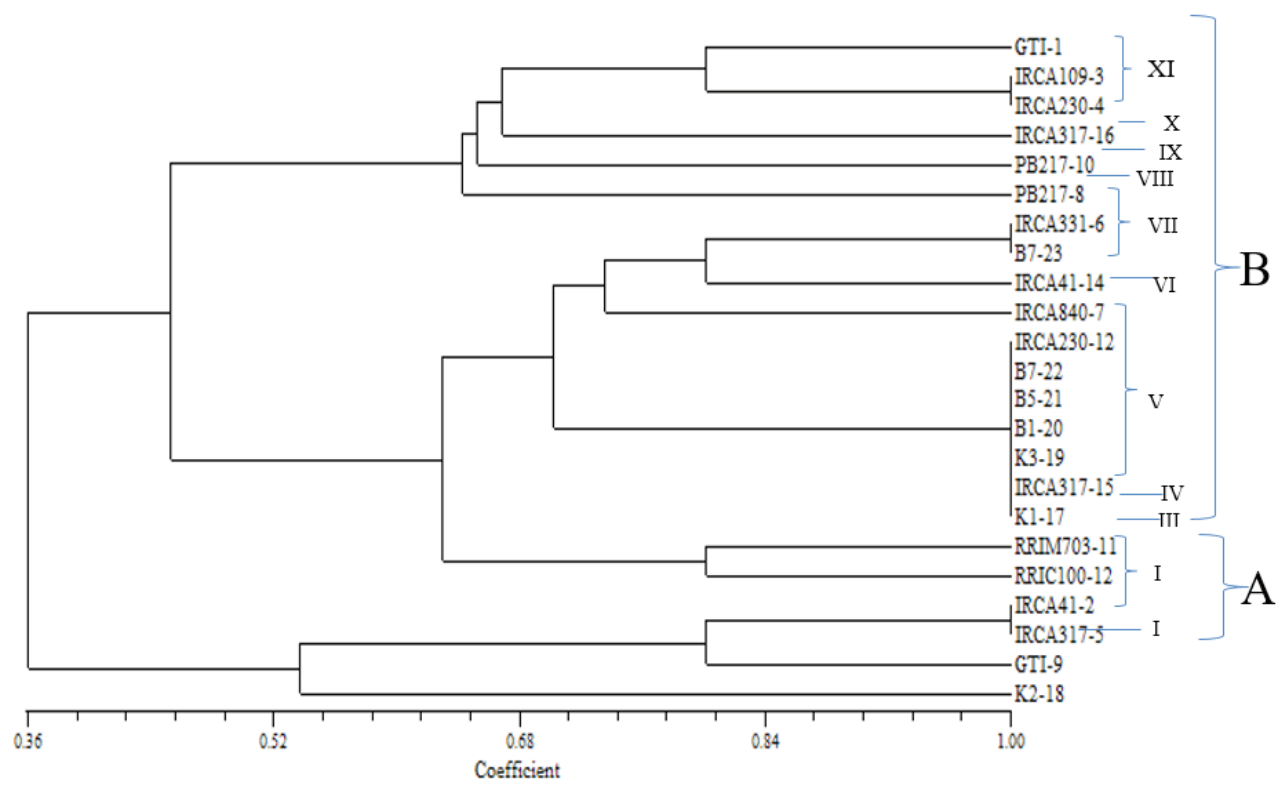

Figure 02: A dendrogram showing genetic diversity/similarity revealed by 5 simple sequence repeat primers among $23 \mathrm{H}$. brasiliensis clones cultivated in Ghana 
Contrarily, cluster B was further divided into three sub-clusters at $44.8 \%$ genetic distance. With this, the first sub-cluster B (III-IV) was made up of RRIC100-12 and RRIM70311 (PSG). The second sub-cluster B (V-VII) comprised K1-17, K3-19 (Kade), B1-20, B521, B7-22, B8-23 (Bunso), IRCA317-15, IRCA230-12, IRCA41-14 (PSG), IRCA840-7 and IRCA331-6 (GREL). The final sub-cluster $\mathrm{B}$ (VIII-XI) consisted of such rubber clones as PB217-8, IRCA230-4, IRCA109-3, GT1-1 (GREL), PB217-10 and IRCA317-16 (PSG) (Figure 02).

At genetic distance of $100 \%$; IRCA3175, IRCA41-2, IRCA331-6, IRCA230-4, IRCA109-3 (GREL) and B8-23 (Bunso) were genetically similar. Moreover, rubber clones consisting of K1-17, K3-19 (Kade), IRCA31715, IRCA230-12 (PSG), B1-20, B5-21 and B722 (Bunso) were genetically similar at genetic distance of $70.4 \%$. Also, at genetic distance of $80.0 \%$ rubber clones GT1-9, RRIC100-12, RRIM703-11, IRCA41-14 (PSG) and GT1-1 (GREL) were similar genetically (Figure 02).

In contrast, $H$. brasiliensis clones including K2-18 (Kade), IRCA840-7, PB217-8 (GREL), PB217-10 and IRCA317-16 (PSG) at different genetic distances of $53.6 \%, 73.6 \%, 64 \%$, $65.6 \%$ and $66.8 \%$ respectively were genetically dissimilar (Figure 02). The farthest genetic distance was shown between Hevea brasiliensis clones K2-18 (Kade) and GT1-1 (GREL) (Figure 02).

\section{DISCUSSION}

There was genetic diversity and similarity present in Hevea brasiliensis clones from the four different geographical areas of rubber production in Ghana which has been shown by the dendrogram (Figure 02). The dendrogram generated a linkage among the Hevea brasiliensis clones at genetic distance of $36.0 \%$ where two clusters were formed.
It was observed that some rubber clones were genetically similar irrespective of their geographical location of growth which could be as a result of their development from budding of clones with scions of similar genetic constitutions. These possible similarities were revealed in rubber clones IRCA317-5, 1RCA412, IRCA331-6, IRCA230-4, IRCA109-3 (GREL) and B8-23 (Bunso) which were linked at $100.0 \%$ genetic similarity level. This supports a controversial result reported by Cesar et al., (2006) and Lekawipat et al., (2003) to express that some relationship existed between geographical areas and sample collection. Introduction of planting materials into Ghana from other rubber-producing countries could have facilitated the distribution of genes in various clones irrespective of the country where they were initially bred.

At a genetic distance of $70.4 \%, H$. brasiliensis clones K1-17, K3-19 from Kade; B1-20, B5-21, B7-22 from Bunso and IRCA31715, IRCA230-12 from PSG showed genetic similarity. Furthermore, at $78.4 \%$ level of similarity, $H$. brasiliensis clones; GT1-9, RRIC100-12, RRIM703-11, IRCA41-14 from the same growing area, PSG and GT1-1 from GREL showed to be genetically similar. High genetic similarity among clones could be as a result of the same parent plants selected for breeding programme over the years. The high genetic similarity suggests a narrow genetic diversity among the clones and this may be explained by clonal propagation employed in establishing plantations (Nakkanong et al., 2008). Genetic similarity could occur because generally vegetative propagation is known to maintain traits of parental lines (Varghese et al., 1997). Genetic similarity assessment might be useful in selecting the parents for a rubber breeding and propagation programme aimed at obtaining heterosis effects and high productivity. Microsatellite primers provide a large quantity of polymorphic information, for this reason they are ideal for differentiating genotypes that are genetically very similar (Nakkanong et al., 2008). This was very much shown in this current study. 
Contrarily, $H$. brasiliensis clones K2-18, IRCA 840-7, PB217-8, PB217-10 and IRCA31716 from different geographical zones did not show any genetic similarity with other clones indicating genetic variability among the genotypes. Genetic diversity observed could be attributed to cross-pollination between the genotypes since rubber tree is out-crossing. Controlled pollinated species produce legitimate genotypes whilst open pollination results into illegitimate genotypes even if similar parents are from different groups (Gouvéa et al., 2010). Genetic differences emanate from gene flow among populations through seed and pollen dispersal. The genetic variability may have been influenced by gene mutation, although it has low incidence rate in $H$. brasiliensis species (Nakkanong et al., 2008). Varghese et al., (1997) reported that it could happen because the rubber tree is a cross pollinated plant and very heterozygous. Also, segregation causes proportion of hybrid alleles from parents to vary. Independent assortment and segregation do occur in highly heterozygous clones, thus the proportion of primer alleles in the $\mathrm{F} 1$ hybrids can greatly differ. Consequently, true nature of genetic relatedness may not be shown in highly heterozygous species of similar pedigree and ancestry (Gouvéa et al., 2010).

\section{CONCLUSION}

A dendrogram was constructed with the unweighted pair group method with arithmetic averages (UPGMA) on the basis of the diversity/similarity coefficients. The band size ranged from 100 to 650 base pairs. With the number of primers employed for the study some rubber clones (IRCA317-5, 1RCA412, IRCA331-6, IRCA230-4, IRCA109-3, B8-23, K1-17, K3-19, B1-20, B5-21, B7-22, IRCA317-15, IRCA230-12, GT1-9, RRIC10012, RRIM703-11, IRCA41-14 and GT1-1) showed genetic similarity even from diverse geographical areas. On the other hand, rubber clones such as K2-18, IRCA 840-7, PB2178, PB217-10 and IRCA317-16 also with regardless to their geographical origins showed some level of genetic dissimilarities. Therefore, for the purposes of propagation and breeding programme of $H$. brasiliensis, some local clones could be selected based on their genetic differences and relatedness.

\section{RECOMMENDATIONS}

DNA extraction protocol of $H$. brasiliensis should be modified, especially by adding polivinylpolipyrolidon (PVPP) to obtain high quality and pure DNA for amplification. Also, PCR amplicons could be ran using polyacrylamide gel (PAGE) to find out if quality bands would be obtainable.

Other types of markers such as SNPs and a combination of different markers could be taken into consideration to genetically analyse $H$. brasiliensis clones in Ghana.

Also apart from trying other markers, the number of microsatellite markers could be increased in future research into the genetic differentiation of the Hevea brasiliensis clones grown in Ghana.

\section{ACKNOWLEDGEMENTS}

The authors are most grateful to the late Elder Charles K. Hayford who supported and sponsored this research. We are also thankful to Prof. Harry Amoatey and Prof. Kenneth E. Danso and all the scientists and technicians of the Biotechnology and Nuclear Agriculture Research Institute of Ghana Atomic Energy Commission for the unrestricted accessibility to their resources. 


\section{REFERENCE}

Besse, P., Lebrun, P., Seguin, M. and Lanaud, C. (1993). DNA fingerprints in Hevea brasiliensis using human minisatellite probes, Heredity. 70: 237-244. DOI: http://dx.doi.org/10.1038/ hdy. 1993.35

Cesar, A., Lucia, A., Rafael, A. and Mario, L. (2006). Analysis of genetic variation in clones of rubber (Hevea brasiliensis) from Asian, South and Central American origin using RAPD markers, Revista Colombiana de Biotechnologia. 8: 29-34. DOI: http://dx.doi.org/10.22302/ iribb.jur.mp.v70i2.127

Doyle, J., and Doyle, J. (1990). Isolation of plant DNA from fresh tissue, Focus. 12: 13-15. DOI: http://dx.doi.org/10.1007/978-3-642-83962-7_7

Feng, S., Wu, Y., Li, W., Yu, F. and Wang, J. (2012). Analysis of Genetic Diversity and SSR Allelic Variation in Rubber Tree. In: The Molecular Basis of Plant Genetic Diversity. (Prof. Mahmut Caliskan Eds.), InTechnology. 135-150. DOI: http://dx.doi.org/10.5772/34408

Feng, S., Li, W., Huang, H., Wang, J. and Wu, Y. (2009). Development, characterization and crossspecies/genera transferability of EST-SSR markers for rubber tree (Hevea brasiliensis), Molecular Breeding. 23:85-97. DOI: http://dx.doi.org/10.1007/s11032-008-9216-0

Hodgkin, T., Brown, A.H.D., van Hintum, T.J.L. and Morales, E.A.V. (1995). Core Collections of Plant Genetic Resources, John Wiley \& Sons, UK. 76-95. DOI: http://dx.doi.org/10.1017/ s0021859600074967

Kalia, R.K., Rai, M.K., Kalia, S., Singh, R. and Dhawan, A.K. (2011). Microsatellite markers: an overview of the recent progress in plants, Euphytica. 177: 309-334. DOI: http://dx.doi. org/10.1007/s10681-010-0286-9

Karp, A., Kresovich, S., Bhat, K.V., Ayad, W.G. and Hodgkin, T. (1997). Molecular Tools in Plant Genetic Resource Conservation: A Guide to the Technologies, International Plant Genetic Resource Institute Technical Bulletin. 2 (7): 9-41. DOI: http://dx.doi. org/10.1787/301534422511

Laborda, P.R., Oliveira, K.M., Garcia, A.A.F., Paterniani, M.E.A.G.Z. and Souza, A.P. (2005). Tropical maize germplasm: What can we say about its genetic diversity in the light of molecular markers? Theoretical Application Genetics. 111:1288-1299. DOI: http://dx.doi. org/10.1007/s00122-005-0055-7

Lam, L.V., Thanh, T., Chi, V., and Tuy, L.M. (2009). Genetic Diversity of Hevea IRRDB'81 Collection Assessed by RAPD Markers, Molecular Biotechnology. 42 (3): 292-298. DOI: http://dx.doi.org/10.1007/s12033-009-9159-7

Lekawipat, N., Teerawatanasuk, K., Rodier-Goud, M., Seguin, M., Vanavichit, A., Toojinda, T. and Tragoonrung, S. (2003). Genetic diversity analysis of wild germplasm and cultivated clones of Hevea brasiliensis Müell. Arg. using microsatellite markers, Journal of Rubber Research. 6: 36-47. DOI: http://dx.doi.org/10.22302/iribb.jur.mp.v70i2.127 
Lindqvist, C., Scheen, A.C., Yoo, M.J., Grey, P., Oppenheimer, D.G., Leebens-Mack, J.H., Soltis, D.E., Soltis, P.S. and Albert, V.A. (2006). An expressed sequence tag (EST) library from developing fruits of a Hawaiian endemic mint (Stenogyne rugosa, Lamiaceae): Characterization and microsatellite markers. BMC Plant Biology. 6:1471-2229. DOI: http:// dx.doi.org/10.1186/1471-2229-6-16

Lorieux, M. Ndjiondjop, M-N. and Ghesquie're, A. (2000). A first interspecific Oryza sativa \& Oryza glaberrima microsatellite-based genetic linkage map, Theoretical Application Genetics. 100:593-601. DOI: http://dx.doi.org/10.1007/s001220050078

Mantello, C.C., Suzuki, F.I., Livia, S.M., Gonçalves, P.S., and Souza, A.P. (2012). Microsatellite marker development for the rubber tree (Hevea brasiliensis): characterization and crossamplification in wild Hevea species, BMC Research Notes, 2012. 5:329. DOI: http://dx.doi. org/10.1186/1756-0500-5-329

Mohammadi, S.A. and Prasanna, B.M. (2003). Analysis of Genetic Diversity in crop plant -Salient Statistical Tools and Considerations, Crop Science. 43: 1235-2763. DOI: http://dx.doi. org/10.2135/cropsci2003.1235

Mukhtar, M.S., Rahman, M. and Zafar, Y. (2002). Assessment of genetic diversity among wheat (Triticum aestivum L.) cultivars from a range of localities across Pakistan using random amplified polymorphic DNA (RAPD) analysis, Euphytica. 128: 417-425. DOI: http://dx.doi. org/10.21608/ajas.2015.558

Nakkanong, K., Nualsri, C. and Sdoodee, S. (2008). Analysis of genetic diversity in early introduced clones of rubber tree (Hevea brasiliensis) using RAPD and microsatellite markers. Songklanakarin Journal of Science Technology. 30(5): 553-560. DOI: http://dx.doi. org/10.22302/iribb.jur.mp.v70i2.127

Oktavia, F. and Kuswanhadi, L. (2011). Genetic relationship of Wickham and IRRDB 1981 rubber population based on RAPD markers analysis, Hayati Journal of Biosciences. 18(1): 27-32. DOI: http://dx.doi.org/10.4308/hjb.18.1.27

Pootakham, W., Chanprasert, J., Jomchai, N., Sangsrakru, D., Yoocha, T., Tragoonrung, S. and Tangphatsornruang, S. (2012). Development of genomic-derived simple sequence repeat markers in Hevea brasiliensis from 454 genome shotgun sequences. Plant Breeding. 131: 555-562. DOI: http://dx.doi.org/10.1111/j.1439-0523.2012.01982.x

Roy, C., Nazeer, M. and Saha, T. (2004). Identification of simple sequence repeats in rubber (Hevea brasiliensis), Current Science. 87: 807-811. DOI: http://dx.doi.org/10.1515/sg-2007-0009

Saha, T., Roy, C., and Nazeer, M. (2005). Microsatellite variability and its use in the characterization of cultivated clones of Hevea brasiliensis. Plant breeding. 124(1): 86-92. DOI: http://dx.doi. org/10.1111/j.1439-0523.2004.01053.x

Sirisom, Y. and Te-chato, S. (2014). Assessment of Somaclonal Variations of in vitro-Plants derived from Nodal Culture of Rubber Trees by SSR Markers, Songklanakarian Journal of Plant Science. 7-12. DOI: http://dx.doi.org/10.5511/plantbiotechnology.14.67

Varghese, Y.A., Knaak, C., Sethuraj, M.R. and Ecke, W. (1997). Evaluation of random amplified polymorphic DNA (RAPD) marker in Hevea brasiliensis, Plant Breeding. 116: 47-52. DOI: http://dx.doi.org/10.1111/j.1439-0523.1997.tb00973.x 
A. Antwi-Wiredu, S. Amiteye, A. T. Asare, R. Kusi-Adjei, R. G. Diawuoh, C. O. Aryee, and G. Y. P. Klu

Venkatachalam, P., Geetha, N., Sangeetha, P., and Thulaseedharan, A. (2013). Natural rubber producing plants: An overview, African Journal of Biotechnology. 12(12): 1297-1310. DOI: http://dx.doi.org/10.1002/9781405181099.k0805 